\title{
The Influence of Culture on Trust Judgments in Customer Relationship Development by Ethnic Minority Small Businesses
}

\begin{abstract}
This article explores the influence of culture on trust judgments in customer relationship development by ethnic minority small businesses (EMSBs). Chao and Moon's (2005) 'cultural mosaic' of overlapping 'cultural tiles' is used to develop a generic conceptual model regarding the relationships between multiple cultural identities, trust and customer relationship development. Drawing on qualitative data from semi-structured interviews with 134 Turkish EMSBs in London (UK), our findings contribute to the understanding of how different cultural tiles influence dimensions of trust judgments in relationship development between EMSBs and different customer groups. Seven propositions and a theoretical framework regarding these relationships are offered for future research.
\end{abstract}

Key words: cultural tiles, trust, customer relationship development, ethnic minority small businesses, qualitative research

\section{Acknowledgement}

The constructive comments of the anonymous reviewers and the Associate Editor are acknowledged with gratitude. 


\section{Introduction}

The influence of culture on trust judgments in customer relationships by ethnic minority small businesses (EMSBs) is under-researched in extant literature. Rather, the majority of studies on EMSBs focus on why and how ethnic entrepreneurs start businesses (Aldrich and Waldinger 1990; Basu and Altinay 2002) and factors that influence business growth, in particular formal and informal networks (Bates 1994; Fadahunsi, Smallbone, and Supri 2000) and entrepreneurs' ethnicity, experience and education (Altinay 2008; Basu and Goswami 1999). Conversely, research on the role of trust in customer relationships focuses upon mainstream, non-ethnic firms (Aunier and N'Goala 2010; Buttle 2004; Palmatier, Dant, Grewal, and Evans 2006; Theron and Terblanche 2010) highlighting trust as the central goal for relationship marketing (Berry 1996).

Although the effect of trust on relationship outcomes is well documented (Palmatier et al. 2006), researchers have highlighted the need for, and value of, crosscultural research in trust building (Saunders, Skinner, and Lewicki 2010; Schoorman, Mayer, and Davis 2007) that emphasizes multiple cultural identities and the impact of different elements of culture on different dimensions of trust (Dietz, Gillespie, and Chao 2010). EMSBs in particular operate at the interface between their own culture and those of their co-ethnic, other ethnic minority and mainstream host country customers. These three customer groups are classified in terms of their cultural and national origin (Cui and Choudhury 2002). This classification is pertinent to the EMSB research context and our research focus on the influence of such cultural elements on trust judgments in customer relationship development. Moreover, these differences among customer groups are easily 
identifiable, making consumers well-defined market segments and thus facilitating multicultural marketing planning (Burton 2002; Cui 1997). Specifically, co-ethnic customers see themselves as belonging to the same ethnic group as the EMSB owner, basing their shared membership on those characteristics of their cultural heritage they consider most salient, normally nationality or religion (Mobasher 2007). In this study of Turkish EMSBs in London (UK), co-ethnic customers comprise Turkish speaking customers. In contrast, other ethnic minority customers see themselves as belonging to ethnic groups that are different to both the EMSB owner's and White British whom they consider typical mainstream customers from the host country (Altinay and Altinay 2008). Within this study, other ethnic minority customers are predominately people from AfroCaribbean, Chinese, Indian and Arab communities. EMSBs are at the centre of the cultural and social exchange, making an interesting and relevant context to explore the influence of the different elements of culture on trust judgments in customer relationship development between EMSBs and these customer groups. More specifically, there is a need for a better understanding of how multiple cultural identities and different elements of culture combine to create what Chao and Moon (2005) refer to as 'cultural mosaic' comprising overlapping 'cultural tiles' that influence differentially trust building and customer relationship development. Our study aims to fill this research gap.

Our objectives are to first develop a conceptual model regarding the influence of culture on trust in customer relationships by EMSBs, utilizing Chao and Moon's (2005) concept of cultural tiles. Second, drawing on qualitative data collected through semistructured interviews with 134 Turkish EMSBs, to explore how different dimensions of trust are influenced by specific cultural tiles in relationship development with different 
customer groups. Third, to develop research propositions and an associated theoretical framework that can be tested by future research.

Our exploratory study contributes to the literature at the interface between ethnic minority entrepreneurship and marketing in two ways: Firstly, our focus on Turkish EMSBs in the UK provides new insights from which we develop a theoretical framework regarding the differential influence of multiple cultural identities (represented by different cultural tiles) on trust judgments and relationship development between EMSBs and different customer groups. Although extant research investigating the importance of trust in relationship development focuses on the roles of benevolence, honesty and competence, the influence of specific cultural elements are rarely considered other than for trust in aggregate. Improved understanding of the influence of culture on trust development in customer relationships by EMSBs is therefore likely to require holistic consideration of the relative importance of multiple cultural identities within co-ethnic, other ethnic and mainstream host country customers' relationship situations and how these influence trust building. Secondly, we offer practical insights for EMSBs to develop strategies to break into the mainstream market and for established marketers to effectively segment different customers according to ethnicity, adapting customer relationship development practices accordingly. Additionally, our findings highlight the importance of identifying salient cultural identities in the context of trust judgment and customer relationship building by EMSBs, offering a further application of Chao and Moon's (2005) cultural tiles theory. 


\section{Towards a Conceptual Model of Culture, Trust and Relationship Development}

EMSBs are rooted in the consumer market with better proximity to their customers compared with large firms, research highlighting they are more engaged in entrepreneurial networking activities that involve proactively developing relationships with customers (Jamal 2005). Given the long-term commitment required for customer relationship development, it is not surprising trust has been identified as either an important (McDonald, Rogers, and Woodburn 2000; Wong and Sohal 2002) or the main contributory factor (Buttle 2004). Although relatively limited in number, cross-cultural comparative studies have highlighted the crucial role of trust in meeting challenges businesses face in building and maintaining relationships (Saunders et al. 2010), at the same time emphasizing cultural differences (Schumann, Waggenheim, Stringfellow and Yang 2010). The way in which such trust develops has been argued to be influenced by values based upon the specific cultural contexts in which these business relationships take place (Saunders et al. 2010; Johnson and Cullen 2002). Below, we first discuss the role of trust in customer relationship development and then explore how different elements of culture influence the way in which EMSBs build trust and develop relationships with different customer groups.

\section{Trust and Customer Relationship Development}

Trust is based on the willingness of one party to become vulnerable by relying on the other (Moorman, Deshpande, and Zaltman 1993), this being informed by a belief that the trustee will act in the best interests of the trustor (Morgan and Hunt 1994; Rousseau, Sitkin, Burt, and Carmerer 1998). Other people's actions are therefore an integral part of 
the trustor's decision to trust, enabling judgments of trustworthiness to be made about the other party based on observation and interpretation. Such judgments have been identified as based on three dimensions, namely the trustee's benevolence or positive orientation to the trustor; their integrity, for example their honesty and fairness; and their ability, that is their relevant skills and competence (Mayer, Davis, and Schoorman 1995). These are referred to using similar terms within the customer relationship management literature by Buttle (2004). He argues trust between parties comprises: benevolence - a belief one party will act in the interests of the other; honesty ('integrity' according to Mayer et al. 1995); and competence - a belief the other party has the necessary expertise ('ability' according to Mayer et al. 1995). These reduce the need for formal control, acting as antecedents of a cooperative long-term relationship based on more than just a series of market transactions (Das and Teng 1998).

Building trust is considered as an investment in relationship development with a long-term payoff for both parties (Buttle 2004). Models of trust highlight such investments are based on evidence of the other's motives and character (their trustworthiness) on which the decision to trust is based (Dietz et al. 2010). Where a trusting relationship develops, risk is reduced as each party discloses more about themselves to the other, becoming more reliant (Gillespie 2003). As a result, the relationship deepens and develops through reinforcing cycles of reciprocated trust (Dietz et al. 2010), making it more likely to yield continuing benefits (Mouzas, Henneberg, and Naude 2007). Moller and Halinen (2000) argue trust is a vital component of relationship marketing, which cannot be fully understood without considering the contexts of surrounding cultural elements, a sentiment supported by Dietz et al. (2010). EMSBs are 
grounded in the cultural identities of their own community as well as other identities which exist outside this community, shaping the way relationship development takes place (Jamal 2005). EMSB owners therefore need to consider how elements of their own culture impact on their interactions with customers from co-ethnic, other ethnic and mainstream host country groups. Yet, in spite of its importance, the influence of culture on trust (Saunders et al. 2010), especially in an EMSB environment, remains underresearched. In particular, it is unclear whether and how specific elements of culture might relate to dimensions of trust judgments.

\section{Cultural Identities, Trust and Customer Relationship Development}

In the small business context, the most widely used marketing approaches have been found to be relationships and networks (Coviello, Winklhofer, and Hamilton 2006; Hultman and Shaw 2003; Zontanos and Anderson 2004). Small firms benefit from relationship marketing through acquiring and retaining customers, generating positive reputation and increasing their customer base. Their approach to relationship marketing, however, depends on a number of factors, including the cultural background of the entrepreneur, the business context - such as the sector in which the enterprise operates, and the target customer group (Altinay and Altinay 2008; Carson and Cromie 1990; Wright, Martin, and Stone 2003).

EMSBs are positioned within and traverse multiple cultures, operating in a culturally diverse market place (Dyer and Ross 2000). In developing relationships with their customers, they create a platform for social exchange between marketers and consumers from different cultural backgrounds (Coviello et al. 2006; Omar, Kirby, and 
Blankson 2003; Pires and Stanton 2000). While there are a variety ways of viewing cultural backgrounds, previous research has largely assumed them to be static and, often, synonymous with national cultures (Leung, Bhagat, Buchan, Erez, and Gibson 2005). More recently, researchers have argued culture is dynamic and complex, elements of multiple cultural identities being enabled and constrained by specific contexts (Hind, Liu, and Lyon 2011). Consequently, rather than focusing upon the influence of these different elements per se, the influence of culture on trust judgments might best be understood by examining the full complexity of interrelationships between EMSBs' multiple cultural identities and trust judgments within specific customer relationship development contexts.

Chao and Moon's (2005) concept of a 'cultural mosaic' of overlapping 'cultural tiles' offers a useful framework to explore the extent to which multiple cultural identities contribute to the contexts for such relationship development (Hind et al. 2011). Consistent with the majority of cultural research, a cultural mosaic allows consideration of how value systems differentiate between groups. However, unlike other frameworks, Chao and Moon's (2005) mosaic emphasizes the holistic nature and complexity of culture in two ways: First, it highlights a need to consider both those elements that are common between parties and those that are specific to an individual party. Within the mosaic these comprise three categories of tiles representing demographic, geographic and associative cultural features. Demographic tiles are derived from physical characteristics such as age, gender, race, and ethnic group. Geographic tiles relate to natural or manmade features that can shape identities including locale, region, or country, whilst associative tiles are based on formal and informal groups such as family, religion, 
profession, and other affiliations (Chao and Moon 2005). Each tile therefore represents a cultural identity with its own artifacts, values, and underlying assumptions which may influence an individual's thinking, conduct and interactions with others. Second, each tile also represents an element of the overall underlying culture, varying in importance dependent upon the relationship's context. Cultural tiles can be combined differently as collages (hence 'cultural mosaic'), dependent upon particular relationship situations. For example, the influence of an individual's country of origin (as a geographic tile) may be moderated by the influence of family and social circle (as associative tiles) and/or the influence of age, gender, and education (as demographic tiles). It is the recognition and consideration of the holistic nature and complexity of culture that makes Chao and Moon's (2005) 'cultural mosaic' particularly relevant for exploring the cultural diversity of ESMBs' marketplace, where the cultural elements that shape owners' and customers' multiple cultural identities interact and influence trust judgment in relationship development.

Demographic tiles. Drawing upon Chao and Moon (2005), a person's ethnic group can be considered a strong demographic tile giving a sense of belonging, as well as the emotions and feelings associated with being part of that group (Laroche, Kim, and Tomiuk 1998). More specifically, ethnic group can affect business transactions between EMSBs and co-ethnic and other customers (Jamal 2003). Ethnic entrepreneurs find it easier to deal with co-ethnic customers transacting business in a language with which they are familiar (Werbner 1990); this allowing them to establish clearly the needs and requirements of such consumers. Their shared ethnicity enables them to better understand their decision making approaches and buying behaviors (Gremler and 
Gwinner 2000; Holden and Burgess 1994; Pires and Stanson 2000) as well as likely influencing factors (Phillips, Doole, and Lowe 1994). In such situations, close ties provided by common demographic tiles help create a harmonious relationship based on a perceived mutuality of thinking (Ekinci, Dawes, and Massey 2008), providing a basis for predicting how people will react in a relationship and thus building trust (Dietz et al. 2010). While exploring the distinct marketing strategies of ethnic entrepreneurs of Chinese, Korean, South Asian, and Jewish origins, Iyer and Shapiro (1999) find ethnic minority entrepreneurs exploited close ties with their co-ethnic communities, informal networking and relationship marketing molding their marketing practices. This ethnic dimension in marketing practices was also revealed in studies of the marketing strategies of ethnic retail entrepreneurs in the UK and the USA, respectively (Altinay and Altinay 2008; Jaebeom, Swindler, and Sunhee 2006; Jamal 2005). These indicate customers' direct service experiences in their native cultures, based on demographic tiles such as ethnic group and language, appear to be the major influences on trust, easing relationship development. Consequently, ethnic group, as a demographic tile could act as a direct antecedent of trust between EMSBs and co-ethnic customers, influencing the way consumers perceive marketing stimuli (Figure 1).

Geographic tiles. Originating from the same geographic region or country can also be an antecedent of cultural affinity. Geographic tiles, such as common country of origin, region, and locale, create an environment of personal connection and similar values to those emerging from demographic tiles (Chao and Moon 2005) supporting the development of trust (Dietz et al. 2010). Swift (1999) claims cultural closeness through place can particularly facilitate interactions between customers and their service/product 
provider as they find common ground. Dyer and Ross (2003) highlight the importance of these socio-cultural relationships. They observe that informal discussions between business owners and their customers are often concerned with similarities and differences between the host country and their country of origin, or problems that exist for members of their co-ethnic and other ethnic groups. Studies of small businesses also confirm the importance of community embeddedness in facilitating meaningful interpersonal relations between the business owners and customers (Coca-Stefaniak, Parker, and Rees 2010). Common cultural features represented by geographic tiles such as country of origin, region, and locale can therefore support cultural affinity, helping create an environment of trust between parties (Figure 1).

Associative tiles. Literature suggests demographic and geographic tiles are often reinforced by associative tiles (Dietz et al. 2010), representing groups with whom individuals choose to identify (Chao and Moon 2005). Membership of family and religious and professional communities provide a strong sense of social identity, supporting formation of distinctive 'subcultures' and creating closer ties and trust amongst individuals (Meyerson, Weick, and Kramer 1996). Affinity marketing literature suggests such associative tiles facilitate relationship development and continuity between businesses and customers (Macchiette and Roy 1993; Mekonnen, Harris, and Laing 2008; Swift 1999). In studies of EMSB marketing practices, Jamal (2005) and Altinay and Altinay (2008) find family members and customers from the same religious background comprised the customer base of some EMSBs, shopping with family or co-religion businesses being seen as a strong sign of solidarity amongst group members. Studies also suggest reputation deriving from EMSBs' professional or association memberships can 
contribute to trust formation and thus relationship development (Mekonnen et al. 2008; Meyerson et al. 1996) (Figure 1). However, there is a dearth of empirical studies confirming or refuting these assertions. Therefore, the effects of such associative tiles remain to be investigated.

Figure 1 summarizes our conceptual model incorporating cultural tiles, the three dimensions of trust and customer relationship development with these customer groups. This conceptual model proposes there is a relationship between cultural elements, dimensions of trust and customer relationship development with different customer groups. However, it is unclear how the dynamic aspects of cultural identities interact. In particular whether specific cultural elements influence specific dimensions of trust judgments and if this differs between customer groups. This exploratory study aims to fill this research gap by offering insights into how different specific cultural elements might relate to specific dimensions of trust judgments in relationship development between EMSBs and different customer groups.

\section{Insert Figure 1 here}

\section{Research Design}

Our analysis is based on qualitative data collected from Turkish EMSBs in London (UK) through 134 face-to-face semi-structured interviews with Turkish-speaking ethnic minority entrepreneurs. Such an approach can support development of a better understanding of the subject matter (Denzin and Lincoln 2011). It is especially promoted by culture and entrepreneurship researchers such as Dyer and Ross (2000), Jamal (2005), 
Sackmann (1991), and Sarasvathy (2004). For example, Jamal (2005) and Dyer and Ross (2000) adopt a qualitative approach to study the types of interactions ethnic minority business owners had with their customers as they marketed themselves, their products and their services and to build theory. Such an approach is particularly pertinent to research into social and cultural facets of organizations, as it:

“...focuses on insiders' perspectives, their everyday theories of organizational life, and what they consider relevant in that particular setting....... This approach enables the researcher to enter and explore with the respondent his or her phenomenal world and the cognitive frameworks that come to bear, and ultimately, to learn the respondent's point of view." (Sackmann 1991: 305)

In our study, the qualitative approach is used because limited theory exists to explain the relationships among cultural elements, trust judgment and customer relationship development. Indeed, the majority of entrepreneurship research has used the quantitative approach to examine relationships of well-defined variables whilst very few studies have adopted a process-theoretic approach that seeks to qualitatively open the black box of entrepreneurship phenomenon to generate new insights (Chiles, Bluedorn, and Gupta 2007).

The sample was drawn from a database of 1,200 Turkish speaking entrepreneurs who owned a small business in different boroughs of London. Due to the absence of any complete listing of this EMSB population, we constructed this database from directories and unpublished lists of names obtained from the Turkish High Commission. Further entrepreneurs who met our criteria were identified via ethnic newspapers including Kibris Gazette, Toplum, Postasi and Olay Gazetesi, and the Turkish Cypriot Chamber of Commerce in London. Although we were unable to evaluate the representativeness of our 
database statistically, informal information provided by gatekeepers suggested our database covered the full range of sectors in which Turkish EMSBs operated. From this we selected a random sample, stratifying participants by sector to ensure that any patterns that did emerge would be of particular interest and value and represent the key themes across the full range of Turkish EMSBs in London.

Interviews of approximately one hour's duration were undertaken with EMSB owners in retailing (45), professional and other services (45), manufacturing (29) and wholesale (15) sectors. We observed technology-based EMSBs were less likely to participate. For example, six information technology EMSBs declined to contribute to the study on the basis of confidentiality and sensitivity of their business practices. stated explicitly that they operated in a very competitive environment where 'knowledge' is competitive advantage and therefore cannot be shared. Among participating EMSBs, 114 (85.1 percent) were micro businesses (1-9 employees) and 20 (14.9 percent) small businesses (10-49 employees); 20 (14.9 percent) were recent start-ups (up to three years) and 114 (85.1 percent) had been in operation for three or more years. Following discussion of an information sheet and obtaining of consent, each interview was conducted in either English or Turkish at the participant's request. Interviews commenced with a defined schedule of initial questions, follow-up prompts being dependent upon initial responses; all were audio recorded and transcribed fully. Each interview covered a wide range of issues including customer profiles, relationship marketing practices and how the entrepreneur managed relationships with co-ethnic, other ethnic and British mainstream customer groups, their understanding of trust and its 
importance in relationship development, how trust could be built and in particular the role of cultural affinity in relationship development (see Appendix 1).

Interview transcripts were analyzed initially following the approach recommended by Corley and Gioia (2004). First, we identified emerging concepts and grouped them into categories using open coding (Corbin and Strauss 2008) to generate the first-order concepts. Wherever possible participants' language was used to create in-vivo codes. Second, following Corley and Gioia (2004), we used axial coding to introduce our own interpretations, categorizing these first-order concepts into broader second-order themes. For example, data coded 'start conversations', 'give attention', 'make feel at home' and 'family atmosphere' were categorized as 'demonstrate family atmosphere' (Figure 2). Third, the second-order themes were gathered into a series of aggregate dimensions rereferring to the original data to check our interpretations (Table 1). These were the three dimensions of trust judgments outlined in our conceptual model (Figure 1). Our goal here was to understand how the previously identified themes constituted different elements of trust. For example, it emerged that demonstrating family atmosphere, generosity and friendship were strong signs of benevolence; whilst ethical principles and quality consistency indicated honesty. Professional principles and demonstrating professionalism were clear signs of competence (Figure 2). During axial coding, themes emerging from each researcher's independent categorization of the transcripts were cross-checked, discussed, compared and where necessary re-categorized. These provided the basis for an overarching theoretical framework of culture, trust judgments and relationship development (Figure 3), which emerged from the data analysis. 


\section{Insert Figure 2 and Table 1 here}

Concurrently a content analysis of each transcript was undertaken to identify whether specific cultural tiles affected different dimensions of trust. This involved initially using axial coding to categorize concepts according to different cultural tiles (Table 2) and then breaking down data by asking questions such as: What? How? When? How much? and using theoretical memos (Corbin and Strauss 2008). Our conceptual model (Figure 1) provided a lens to explore additional themes that did not emerge from this inductive analysis. Theoretical memos ensured each of our comments, thoughts and insights regarding links between different dimensions of trust and cultural tiles were recorded initially, being updated as our analysis progressed.

\section{Insert Table 2 here}

Selective coding was used to integrate the theoretical memos with our secondorder themes and aggregate dimensions. This also involved re-visiting the data to explore inter-relationships indicated by our conceptual model. In conjunction with our theoretical memos these data were sifted and charted, diagrams representing both overlapping issues and the differences in terms of the influence of culture on trust and customer relationship development for each of the customer groups. The final stage of our analysis involved enfolding the literature and finalizing the theoretical framework. During this, we compared and contrasted the emerging framework with the extant literature to improve 
construct definitions, and therefore build internal validity prior to creating propositions that could inform future research.

\section{Research Findings and Propositions}

Building on the conceptual model we developed, our remaining two objectives are: to explore how different dimensions of trust are influenced by specific cultural tiles in relationship development with different customer groups; and to develop research propositions and an associated theoretical framework that can be tested by future research. We now report our findings related to these objectives.

\section{Benevolence and Relationship Development}

EMSBs perceived relationship marketing as a competitive advantage over large established firms with the financial muscle to combine transactional, such as pricing, promotion and advertising, with relational approaches to marketing. They considered relationship development as a process of 'social exchange', something they saw as a weakness of their large counterparts. The vast majority of EMSB owners explained how they tried to ensure that customers felt there was a family atmosphere, indicating this was the most important element of Turkish hospitality. A retail shop owner emphasized the importance of being sincere and demonstrating good intention: Our biggest strength is that we have a lot to offer from our hospitable culture. When the customers go to the bigger stores, they do not know the employees very well. Employees do not talk to them properly. They sometimes do not even know the products well. Whereas with us, I talk to customers informally, I talk to them about football, traffic, weather, family and develop 
an informal relationship. Looking after the customers and 'demonstrating generosity' has also been indicated as an important element of trust. Informants went further and stated that they acquired what they called 'core values' either as a business owner or as a customer in their countries of origin before starting businesses in the UK, claiming these values inspired them in relationship development activities with customers. A restaurant owner's comments illustrated this as: Customer relationships are very important and we have a lot to offer here from our culture. We are very generous when it comes to sharing food or offering food, offering things which would not cost a lot and customers love this. We offer more than enough. During our interviews, most participants highlighted the importance of demonstrating friendship in business transactions. They stated that this mindset inspired them in their relationship development with customers. Starting dialogue with customers was perceived to be an effective way of demonstrating friendship and good intentions. One grocery shop owner explained: We are very good at developing customer relationships. We take the initiative and start off conversation with our customers about anything. An accountant's comments summarized the 'mentality' dominating the trust development with customers: We treat them as 'people' not as customers. We value them with their characters and personalities.

In line with arguments by Carson and Gilmore (2000) and Altinay and Altinay (2008), our findings revealed that the value sets of the business owner determine the marketing orientation of firms. Since relationship development was well embedded in the values of Turkish EMSB owners who saw this as a competitive advantage over large counterparts, they equated relationship marketing to their firms' marketing philosophy. Our study also identified EMSB owners as key players in relationship development 
stressing the importance of considering their socio-cultural values. This is something which has been neglected by previous studies (Hultman and Shaw 2003; Jamal 2005). As suggested by Fletcher and Fang (2006), culture influences all the players including business owners in relationship development.

Demographic Tiles, Benevolence and Relationship Development. There was a widespread view among the Turkish business owners that being part of an ethnic minority group and sharing a common ethnicity helped build what they called 'natural trust' between themselves and co-ethnic customers, emphasizing the ethnic group demographic tile. Foregrounding of a common Turkish ethnic group when demonstrating benevolence was typified by an accountant who, after emphasizing the confidentiality issues in his business, expressed his views about his customers: Most of my customers are Turkish. They trust me because I am Turkish too. They think they can express themselves better, feel confident with us. They think we can protect their rights better. This suggested a common ethnic group tile informed Turkish (co-ethnic) customers' belief that the business owners were credible and would act in their interests even before the development of a relationship. A common language also appeared to act as an antecedent for benevolence trust, typified by one hairdresser's response. I have many Turkish customers because of the fact that I am Turkish. It makes them feel comfortable with me.

This is a trust factor. Turkish people come to me because they can express themselves in Turkish language. Turkish customers can speak Turkish to me. In addition, Turkish customers are culturally very different, they are very keen to have a style and get their hair done properly. Of course using the same language helps. Also, they know that we would understand them and be patient with their needs because we know the culture well. 
These findings confirmed the arguments of Jamal (2005) and Jaebeom et al. (2006) who stated that close cultural ties help the development of trust and thus ease relationships between EMSB owners and co-ethnic customers. Cultural affinity through shared membership of the same ethnic group and a common language informed Turkish customers' belief these business owners were credible and would act in their interests even before the development of a relationship. These were the essential elements of interpersonal trustworthiness and benevolence trust identified by Buttle (2004) and Mayer et al. (1995) respectively. In line with the arguments of Gremler and Gwinner (2000), such cultural affinities provided EMSB owners with a means of identifying and understanding likely expectations of co-ethnic customers. This suggests our first two propositions:

Proposition 1: Shared ethnic group is associated positively with the benevolence dimension of trust in EMSB relationship development with co-ethnic customers.

Proposition 2: Common language is associated positively with the benevolence dimension of trust in EMSB relationship development with co-ethnic customers.

Geographic Tiles, Benevolence and Relationship Development. Commonalities in the form of other geographic tiles also acted as antecedents of benevolence trust in the case of other customer groups. Despite belonging to different ethnic groups, the distinctiveness of their country of origin from the host country acted as a point of coidentification between ethnic Turkish businesses and other ethnic customers. One of the 
retail shop owners stated bluntly: Most of my customers are Chinese and colored. We are foreigners, they are foreigners, therefore we get along well. It was also typified by an accountant who commented: I have Greek customers. We get along well on a foreign land. Geographic cues were also demonstrated through being from the 'same region', a retail shop owners stating: We have many customers from the Mediterranean and Middle East region; Turkish Cypriots, Kurdish and Arabs. We come from the same region. We share similar history, traditions and values. We find many things in common to talk about. Similar food, drink and culture always dominate our conversations. Participants perceived originating from a similar region or country with similar traditions and history allowed stronger emotional ties in business transactions, acting as a precursor of good intention and benevolence.

These findings are in line with the arguments of Swift (1999) and Fletcher and Fang (2006) whose research supported the idea that geographic tiles, in particular commonality of region or origin, ease the relationship development and interactions between the customers and the service providers. They also provided support to CocaStefaniak et al. (2010) who indicated that geography is influential in facilitating relationship development when service providers and customers have commonalities. For other ethnic customers these appeared to act as antecedents of benevolence trust, prompting our third proposition:

Proposition 3: The country of origin being different from the host country is associated positively with the benevolence dimension of trust in EMSB relationship development with other ethnic minority customers. 
In the case of UK (mainstream host country) customers, the immediate locale provided small business owners with a point of co-reference. For these customers the EMSB being part of the local community was particularly important in relationship development, Turkish business owners being perceived as 'local'. Almost all EMSB owners whose businesses had been in existence for three or more years in the locale talked about 'being local' with pride, regarding it as one of the key contributors to interpersonal relationships and benevolence. One participant summarized this: I am part of the community. I am local. We are in this business [for] 32 years. There are mums who come here with their babies. They are residents of this area. I know their childhood. They call me 'uncle'. We do not invest much in marketing. We have many of these local customers and we know that they have a certain perception before they come to us. Another, regarding 'locality' as a competitive advantage, stated: Other hairdressers are our competitors. However, we are more established in the region. We are local. People in the area know us. We offer local people help for everything. We have good relationships with our customers. Yet another commented that 'being local' not only helped develop relationships but also made customers emotionally loyal to the business: We have loyal customers because we are more established compared to the next door. We make people feel that this is their local shop. We have customers who have been with us for ages. They come here until they die.

These findings supported studies by Coca-Stefaniak et al. (2010) and Swift (1999) who found that localization and community embeddedness led to more interpersonal relations and contributed to the development of benevolence trust. Mutual identification 
represented by the 'immediate locale' geographic tile offered a clear point of similarity. 'Being local' in the neighborhood appeared to help establish benevolence and initiate the relationship in the case of mainstream customers, hence our fourth proposition:

Proposition 4: A shared locale is associated positively with the benevolence dimension of trust in EMSB customer relationship development with mainstream host country customers.

\section{Honesty and Relationship Development}

When we considered the interface between honesty and relationship development we found EMSB owners often made reference to 'ethical principles'. A retail shop owner commented: Work ethics are important. You should not cheat on your customers. You need to follow fair trade, make sure that you gain the trust of the customers. If you cheat on them, they will sooner or later find out the truth. Confirming this, a small grocery shop owner stated: Business ethics has been emerging as an important issue. You have to be honest with your customers. Do not try to rip them off if you want to gain their trust. When questioned further, EMSB owners emphasized how they focused on the quality of products and services. Ethnic minority catering businesses paid particular attention to the quality of raw materials such as meat, burgers and cheese, presentation and hygiene of the outlets, and the ability of their workforce to offer high quality and consistent hospitality service. EMSBs operating in professional services such as insurance, law and architecture firms devoted attention to the reliability and effectiveness of the advice and the service. 
It was apparent that honesty could be demonstrated through meeting or exceeding customers' expectations regarding the quality of the products and services offered. This was particularly important because a gap between customers' expectations of the quality of the products and services could jeopardize trust. An accountant explained: We are honest and we do not raise expectations. We do not promise things that we cannot do. Honesty is important in this business. You have to be honest with everyone. When a case is too complicated we go to co-ethnics who are specialists in this area. We don't promise things that we cannot deliver. Participants stated further that consistency of quality in their offers was extremely important for the customers in their competitive environment. A restaurant owner commented: You will get known by the customers at the start up with the quality of the products and services that you offer. If you choose to go down the route of reducing the quality or increasing the price without offering added value once you get established, this will not be well received by the customers. Participants observed that switching costs of customers were not high and, in general, loyalty was declining. Inconsistency in the quality of products and services could, they felt, damage trust development or jeopardize existing trust, resulting in loss of market to their competitors.

Associative Tiles, Honesty and Relationship Development. Associative tiles, in particular religion and profession/association membership, were associated with the judgment of honesty in relationship development. The influence of religion was immediate in the case of the relationships between Turkish EMSB owners and their coethnic and other ethnic Muslim customers. One retail shop owner emphasized the importance of shared religion as a precursor of 'social solidarity': We have many Muslim customers who shop from us. I know that they come to us because we sell good quality 
products but there is another element to it. That is brotherhood. A meat manufacturer went further and stated that, besides acting as a sign of cultural affinity and facilitating benevolence, common religion is seen as the strong sign of honesty: I have many Muslim customers. They know that our meat is 'halal' and they will not breach their religious beliefs when they buy meat from us.

These findings demonstrated the importance of social identity (Macchiette and Roy 1993; Mekonnen et al. 2008). In line with findings of Jamal (2005) and Altinay and Altinay (2008), common religion as an associative tile helped build honesty trust with both co-ethnic customers and other ethnic customers leading to cultural closeness and creating implicit bonds. EMSBs' customers, in particular those who were conservative and shared the same religion, took it for granted that 'business owners are there to represent their interests with all honesty'. A financial advisor, who emphasized he had many Muslim customers with Turkish, Arab, Malaysian and Pakistani backgrounds, stated it was an implicit belief among his customers that he was honest: Muslim customers know about my religious background. They trust me, they know that I would be honest with them and will not get them involved in a deal that would require them to pay interest or earn interest. We all know that it is haram (meaning forbidden by Qu'ran)'. Our fifth proposition is therefore:

Proposition 5: Common religion is associated positively with the honesty dimension of trust in EMSB customer relationship development with co-ethnic and other ethnic minority customers. 
The interviews highlighted that for some customers EMSB owners considered honesty could not be shown unless they demonstrated certain skills, competences, and expertise. In particular, professional identity and association membership as endorsement of skill sets and competences were perceived as a strong sign of honesty by mainstream host country customers. These associative tiles (identified by Mekonnen et al. 2008; Meyerson et al. 1996) helped initiate a relationship with mainstream host country customers. Membership of professional associations, such as Association of Chartered Certified Accountants, Association of British Insurers and the Association of Plumbing and Heating Contractors was seen as the evidence of quality, transparency, and ethical business practice that facilitated relationship development. An accountant emphasized: Unfortunately, intentionally and unintentionally, some of the accountants in our community got involved in money laundering. This is not a good reputation for us as Turkish accountants. I had to become a member of the Accounting Association in order to be able to gain the trust of English customers that I am an honest and reliable accountant. They can come to me and develop business relationships like they do with an English accountant. Confirming this, a plumber stated: There are many plumbers around who are not certified. My certification and membership to the Association of Plumbing and Heating Contractors make English customers realize that I have no choice but to be honest. That helps me to develop relationship with them and break out to mainstream market as well. EMSB owners therefore had to respond to mainstream host country customer expectations, endorsing their skill sets and competences through professional association or membership. This suggests our sixth proposition: 
Proposition 6: EMSB owners' professional identity is associated positively with the honesty dimension of trust in relationship development with mainstream customers.

\section{Competence and Relationship Development}

Alongside benevolence and honesty trust, developing competence trust appeared to be extremely important in relationship formation with all customer groups. In particular, EMSBs needed to possess and demonstrate appropriate skills and competences to complement goodwill trust and develop relationships with customers. A Turkish accountant who had a diverse portfolio of customers emphasized that responding to the needs of the customers on time and professionally was one of the requirements of developing trust. Confirming the importance of competence and professionalism, a meat manufacturer also stated: My difference from competitors is I always invest in professionalism and quality. I work hard as a real professional and I gain the trust of my employees, customers, [and] suppliers through my work quality. Similarly, an automotive engineer claimed that by active engagement in service delivery activities he was able to demonstrate his competences and thus build competence trust. He went further and stated that his automotive knowledge and skills contributed to the development of competence trust: Knowledge and experience are crucial in this business. In this business, customers are knowledgeable as well and they can easily understand if you are 'waffling'. You have to make customers feel confident that you know the business. Most of the business owners were of the opinion that trust with the customers could not be developed solely on the basis of benevolence and honesty. They therefore needed to develop personal and 
organization-specific competences, skills, and knowledge in order to be able to address the expectations of diverse customer groups associated with competence trust.

Associative Tiles, Competence and Relationship Development. Further evidence regarding the role of associative tiles in the development of competence trust suggested that academic achievement or membership of a professional association provided customers with confidence that their interests would be represented and their needs addressed properly. Participants stated that having a degree from a British university was a strong sign of competence and expertise in the eyes of all customer groups. This was particularly the case for professional services businesses. An accountant comparing himself with others who completed their degrees in Turkey commented: I got my accountancy degree from a United Kingdom University. It makes a huge difference in the eyes of customers. It is seen as a clear sign of ability to master accountancy in the UK. Similarly, a lawyer stated: My degree is from the UK. Customers know that I have knowledge of laws, rules and regulations in the UK. I can represent their interests better than a lawyer who came here from another country. During interviews, it became apparent that skills endorsed by a reputable organization or institution and membership of an association constituted a source of pride among business owners and, more importantly, considered a source of competitive advantage. These associative tiles were perceived to facilitate the development of competence trust between EMSBs and their customers. During interviews EMSB owners argued that being a member of a restaurants' association, ethnic retailers' association, car mechanics' association or hairdressers' association or a hairdresser working closely with a reputable brand such as 
Toni\&Guy was perceived by customers as a strong sign of consistent high quality and competence.

These findings demonstrated clearly that EMSBs' relationship development activities were moderated by socio-cultural factors in the UK. This provided support for assertion made by Fletcher and Fang (2006) and Omar et al. (2003) who argued that relationship activities were influenced by local culture in which they took place. Turkish EMSBs' relationship development practices were culturally embedded in their home country, but adapted to the realms of the host country. In particular, they ensured their trade and professional identities were recognized independently, supporting Mekonnen et al.'s (2008) and Meyerson et al.'s (1996) assertions that these contribute to the formation of trust and thus relationship development. These social identities were not 'shared' between the EMSB owners and their customers. Instead, they were used to differentiate their businesses from competitors through acting as precursors of competence trust. In particular, during the research process it was noted there were many ethnic retail shops, hair dressers and restaurants within very close geographical proximity creating direct competition to each other. Their survival was argued to be dependent upon breaking out of the ethnic enclave and expanding into the mainstream customer market. Those ethnic businesses possessing professional identity or association membership considered this offered a competitive advantage over their ethnic counterparts when gaining competence trust of all customer groups and developing a strong and sustainable relationship. Hence our final proposition (Figure 3): 
Proposition 7: EMSB owners' professional identity is associated positively with the competence dimension of trust in relationship development with all three customer groups.

\section{A Summary of Research Propositions and a Theoretical Framework}

The propositions regarding the influence of specific cultural tiles on each of the dimensions of trust judgments indicate how EMSB relationships may develop with coethnics, other ethnics, and mainstream host country customers. We now combine these to offer a theoretical framework which can be tested by future research (Figure 3).

Within our framework, Propositions 1 through 4 suggest both demographic and geographic tiles support EMSBs in demonstrating benevolence in their development of relationships with all customer groups. The demographic tiles of shared ethnic group and a common language facilitate this with co-ethnic customers (Propositions 1 and 2), whilst the geographic tile of the country of origin differing from that of the host country appears more important in facilitating benevolence with other ethnic group customers (Proposition 3). In contrast, for mainstream host country customers the shared geographic tile of locale predominates when demonstrating benevolence (Proposition 4).

Propositions 5 and 6 suggest that associative cultural tiles support EMSBs in demonstrating honesty. Within this, EMSBs use different tiles dependent upon whether the relationship being developed is with mainstream host country or other customer groups. For both co-ethnic and other ethnic customers a common religion appears important in facilitating honesty (Proposition 5), whilst for mainstream host country customers professional identity or membership of an association supports demonstrations 
of honesty (Proposition 6), Finally, Proposition 7 indicates this specific associative tile, professional identity or membership of an association, also supports EMSBs in demonstrating competence to all customer groups.

\section{Insert Figure 3 here}

\section{Conclusions}

This article contributes to the literature at the interface between ethnic minority entrepreneurship and relationship marketing. Extant ethnic minority entrepreneurship has largely focused on the start-up and growth of EMSBs, leaving a research gap on the factors influencing customer relationship development. Marketing literature has focused on the role of trust on customer relationship development by mainstream, non-ethnic minority firms, offering little insight regarding how EMSBs develop relationships with different customer groups. Responding to the call for research into the importance of culture in trust building (Saunders et al. 2010; Schoorman et al. 2007), more research is required to understand how EMSBs operating in a culturally diverse market place can exploit different elements of culture to influence particular dimensions of trust in their long-term relationships with customers. Although cultural diversity of customers has attracted the attention of researchers in North America investigating the interface between ethnicity and marketing during the last two decades, there is a dearth of research about the marketing strategies of EMSBs in Europe, in particular in the UK. This article has begun to address this research gap. 
Specifically, our use of Chao and Moon's (2005) 'cultural mosaic' has enabled a focus on cultural diversity and complexity, allowing the emergence of seven propositions incorporating both common and specific elements for the three EMSB customer groups. These provide the basis for our theoretical framework to explain the importance of specific demographic, geographic, and associative tiles in the development of specific dimensions of trust with different customer groups (Figure 3), thereby extending our understanding of the role of EMSBs as cultural mediators. Based on empirical evidence from Turkish EMSBs in London we have identified six distinct cultural tiles that are instrumental to the judgment of different dimensions of trust and consequently customer relationship development. These tiles, representing elements of EMSBs' multiple cultural identities, operate differently dependent upon whether the customers are coethnic, other ethnic or mainstream host country.

Our findings have also charted new avenues for ethnic entrepreneurship research, particularly factors that influence EMSBs' growth. In addition to conventional avenues of studying the roles of formal and informal networks (Bates 1994; Fadahunsi et al. 2000) and entrepreneurs' ethnicity, experience, and education (Altinay 2008; Basu and Goswami 1999), our findings suggest that gaining, maintaining, and retaining different groups of customers (as an important market growth strategy for EMSBs) is reliant on EMSBs' professional competence as a basis of gaining customers' trust. How EMSBs can develop and enhance their professional competence and reputation and most importantly how to communicate and present their professional competence to target customers are therefore interesting questions for future ethnic entrepreneurship research. Within this, it is likely that EMSBs' use of their multiple cultural identities will be dynamic, evolving as 
a function of both context and their experiences (Hind et al. 2011). Consequently, whilst our findings use Chao and Moon's (2005) cultural mosaic in identifying the specific cultural titles relevant to Turkish EMSBs in London, future research may further extend the framework to other contexts. In particular, the use of cultural tiles could direct attention to how multiple identities combine as in a mosaic.

Our findings have important practical implications for EMSBs' customer relationship development. To build trust and develop long-term relationships with customers, EMSBs must create a sense of affinity, emphasizing different cultural tiles to different customer groups. Whilst shared language, ethnicity, religion, identity of being foreign, or even the locale can create affinity leading to benevolence and honesty, they are perceived differently by different customer groups. In contrast, professional competence is fundamental to all customer groups. Understanding these issues is important particularly for those EMSBs aiming to break into mainstream market. Those EMSBs that gain competitive advantage over other ethnic and large established businesses due to these soft elements of relationship marketing also need to develop their skills and competences as a competitive advantage, as trust relationships appear to be sustained by all three categories of cultural tiles. Finally, our findings also have implications for marketers of mainstream brands interested in segmenting customers according to ethnicity and adapting customer relationship development practices to such groups. Large firms which have relied on competence-based relationship development approaches can gain from observing EMSBs' practice of developing 'soft' elements of relationship marketing. They need to avoid a 'one size fits all' approach and instead 
develop strategies which maximize relationship ties with different ethnic minority groups.

As with all research, this study is not free from limitations. However, our hope is that the limitations of this study will direct future inquiry. Firstly, it should be noted our findings are based only on an exploratory study of Turkish EMSBs in one major European city, and hence may not be generalizable to other ethnic minority groups. For example, common religion is an important cultural tile associated with honesty-based trust in Turkish EMSBs, but this is not likely the case in other EMSBs (such as Chinese, Korean, and Japanese) with weak or no religious orientation. Therefore, future research may compare the influence of different cultural tiles on trust judgment and customer relationship development across different customer groups. Second, whilst the qualitative approach enables us to generate insights and open the black box of how cultural elements influence the interaction between EMSB owners and their multicultural customer groups, our study cannot quantitatively predict, nor examine the strengths of, the relationships between cultural tiles, trust judgment and customer relationship development. The strengths of these relationships could be a useful indicator of the importance of each cultural tile in building trust and customer relationships; this in turn could guide EMSB owners when allocating often limited resources. This offers another interesting avenue for future research. 


\section{References}

Aldrich, J., and R. Waldinger (1990). 'Ethnicity and Entrepreneurship,' Annual Review of Sociology, 16, 111-135.

Altinay, L. (2008). 'The Relationship between an Entrepreneur's Culture and the Entrepreneurial Behaviour of the Firm,' Journal of Small Business and Enterprise Development, 15(1), 111-129.

Altinay, L., and E. Altinay (2008). 'Marketing Strategies of Ethnic Minority Businesses in the UK,' The Service Industries Journal, 28, 1-14.

Aunier, P. and G. N'Goala (2010). 'The Differing and Mediating Roles of Trust and Relationship Commitment in Service Relationship Maintenance and Development,' Journal of the Academy of Marketing Science, 38, 303-325.

Basu, A., and E. Altinay (2002). 'The Interaction between Culture and Entrepreneurship in London's Immigrant Business,' International Small Business Journal, 20(4), 371-394.

Basu, A., and A. Goswami (1999). 'Determinants of South Asian Entrepreneurial Growth in Britain: A multivariate Analysis,' Small Business Economics, 13, 57-70.

Bates, T. (1994). 'Social Resources Generated by Group Support Networks May Not Be Beneficial to Asian-Immigrant Owned Small Businesses,', Social Forces, 72(3), 671-689.

Berry, L. (1996). 'Retailers with a Future,' Marketing Management, 5(Spring), 39-46.

Burton, D. (2002). 'Incorporating Ethnicity into Marketing Intelligence and Planning', Marketing Intelligence and Planning, 20 (7), 442-451.

Buttle, F. (2004). Customer Relationship Management: Concepts and Tools. Oxford: Elsevier.

Carson, D., and A. Gilmore (2000). 'Marketing at the Interface: Not 'What' But 'How' Journal of Marketing Theory and Practice, 8(2), 1-8.

Carson, D., and S. Cromie (1990). 'Marketing Planning in Small Enterprises: A Model and Some Empirical Evidence,' The Journal of Consumer Marketing, 7(3), 5-17.

Chao, G. T., and H. Moon (2005). 'The Cultural Mosaic: A Metatheory for Understanding the Complexity of Culture,' Journal of Applied Psychology, 90(6), $1128-1140$.

Chiles, T. H., Bluedorn, A. C., and Gupta, V. K. (2007), 'Beyond creative destruction and entrepreneurial discovery: a radical Austrian approach to entrepreneurship', Organization Studies, 28(4), 467-493. 
Coca-Stefaniak, A. J., C. Parker, and P. Rees (2010). 'Localisation as a Marketing Strategy for Small Retailers,' International Journal of Retail and Distribution Management, 38(9), 677-697.

Corbin, J., and A. L. Strauss (2008). The Basics of Qualitative Research. $3^{\text {rd }}$ Edition. Thousand Oaks, Sage.

Corley, G. K., and A. D. Gioia (2004). 'Identity Ambiguity and Change in the Wake of a Corporate Spin-off,' Administrative Science Quarterly, 49, 173-208.

Coviello, N., H. Winklhofer, and K. Hamilton (2006). 'Marketing Practices and Performance of Small Service Firms,' Journal of Service Research, 9(1), 38-58.

Cui, G. and P. Choudhury (2002). 'Marketplace Diversity and Cost-Effective Marketing Strategies', Journal of Consumer Marketing, 19(1), 54-73.

Cui, G. (1997). 'Marketing Strategies in a multi-ethnic environment', Journal of Marketing Theory and Practice, 5(1), 122-134.

Das, T. K., and B. S. Teng (1998). 'Between Trust and Control: Developing Confidence in Partner Cooperation in Alliances,' Academy of Management Review, 23, 491512 .

Denzin, N. K., and Y. S. Lincoln (2011). 'Introduction: The Discipline and Practice of Qualitative Research.' In The Sage Handbook of Qualitative Research. Eds. N. K. Denzin and Y. S. Lincoln. Thousand Oaks, CA: Sage, 1-20.

Dietz, G., N. Gillespie, and G. Chao (2010). 'Unravelling the Complexities of Trust and Culture,' In Organizational Trust: A Cultural Perspective. Eds. M. N. K. Saunders, D. Skinner, N. Gillespie, G. Dietz, and R. J. Lewicki. Cambridge: Cambridge University Press, 407-423.

Dyer, M. L., and A. C. Ross (2000). 'Ethnic Enterprises and their Clientele,' Journal of Small Business Management, 39(2), 48-66.

Dyer, M. L., and A. C. Ross (2003). 'Customer Communication and the Small Ethnic Firm,' Journal of Developmental Entrepreneurship, 8(1), 19-40.

Ekinci, Y., L. P. Dawes., and R. G. Massey (2008). 'An Extended Model of the Antecedents and Consequences of Consumer Satisfaction for Hospitality Services,' European Journal of Marketing, 2(1/2), 35-68.

Fadahunsi, A., D. Smallbone, and S. Supri (2000). 'Networking and Ethnic Minority Enterprise Development: Insights from a North London Study,' Journal of Small Business and Enterprise Development, 7(3), 228-240. 
Fletcher, R., and T. Fang (2006). 'Assessing the Impact of Culture on Relationship Creation and Network Formation in Emerging Asian Markets,' European Journal of Marketing, 40 (3/4), 430-446.

Gillespie, N. (2003). 'Measuring Trust in Working Relationships: the Behavioral Trust Inventory,' Paper presented at the Academy of Management Conference, Seattle, WA, August.

Gremler, D. D., and K. P. Gwinner (2000). 'Customer-Employee Rapport in Service Relationships,' Journal of Service Research, 3(1), 82-104.

Hind, P., L. Liu, and J. Lyon (2011). 'Putting the Global in Global Work: An Intercultural Lens on the Practice of Cross-National Collaboration,' The Academy of Management Annals, 5(1), 135-188

Holden, N. J. and M. Burgess (1994). Japanese-Led Companies: Understanding How to Make Them Your Customers. London: McGraw-Hill.

Hultman, M. C., and E. Shaw (2003). 'The Interface between Transactional and Relational Orientation in Small Service Firm's Marketing Behaviour: A Study of Scottish and Swedish Small Firms in the Service Sector,' Journal of Marketing Theory and Practice, 11(1), 36-51.

Iyer, G. R., and J. M. Shapiro (1999). 'Ethnic Entrepreneurial and Marketing Systems: Implications for the Global Economy,' Journal of International Marketing, 7(4), 83-110.

Jaebeom, S., J. Swinder, and S. Sunhee (2006). 'Exploring the Role of Culture in Trust Development with Service Providers,' Journal of Services Marketing, 20(4), 265273.

Jamal, A. (2003). 'Marketing in a Multicultural World: The Interplay of Marketing, Ethnicity, and Consumption,' European Journal of Marketing, 37(11/12), 15991620

Jamal, A. (2005). 'Playing to Win: An Explorative Study of Marketing Strategies of Small Ethnic Retail Entrepreneurs in the UK,' Journal of Retailing and Consumer Services, 12, 1-13.

Johnson, J. L., and J. B. Cullen (2002). 'Trust in Cross-Cultural Relationships,' In The Blackwell Handbook of Cross-Cultural Management. Eds. M. Gannon and K. Newman. Oxford: Blackwell Publishers, 335-360.

Laroche, M., C. Kim, and A. M. Tomiuk (1998). 'Italian Ethnic Identity and its Relative Impact on the Consumption of Convenience and Traditional Foods,' Journal of Consumer Marketing, 15(2), 125-151. 
Leung, K., R. S. Bhagat, N. R. Buchan, M. Erez, and C. B. Gibson (2005). 'Culture and International Business: Recent Advances and their Implications for Future Research,' Journal of International Business Studies, 36, 357-378.

Macchiette, B. and A. Roy (1993). 'Affinity Marketing: What Is It and How Does It Work?' Journal of Product and Brand Management, 2(1), 55-66.

Mayer, R. C., J. H. Davis, and F. D. Schoorman (1995). 'An Integrative Model of Organizational Trust,' Academy of Management Review, 20, 709-34.

McDonald M., B. Rogers, and D. Woodburn (2000). Key Customers - How to Manage Them Profitably. Oxford: Butterworth-Heinemann.

Mekonnen, A., F. Harris, and A. Laing (2008). 'Linking Products to a Cause or Affinity Group: Does This Really Make Them More Attractive to Consumers?' European Journal of Marketing, 42(1/2), 135-153.

Meyerson, D., K. E. Weick, and R. M. Kramer (1996). 'Swift Trust in Temporary Groups,' In Trust in Organizations: Frontiers of Theory and Research. Eds. R. M. Kramer and T. R. Tyler. Thousand Oaks, CA: Sage, 166-195.

Mobasher, M. (2007). 'The Iranian Ethnic Community in the United States', In Handbook of Research on Ethnic Minority Entrepreneurship. Ed. L. P. Dana. Cheltenham: Edward Elgar, 228-48.

Moller, K. and A. Halinen (2000). 'Relationship Marketing Theory: Its Roots and Direction,' Journal of Marketing Management, 16(1/3), 29-54.

Moorman, C., R. Deshpande, and G. Zaltman (1993). Relationship between Providers and Users of Market Research: The Role of Personal Trust. Cambridge: Marketing Science Institute.

Morgan, R. M. and S. D. Hunt (1994). 'The Commitment-Trust Theory of Relationship Marketing,' Journal of Marketing, 58(3), 20-38.

Mouzas, S., S. Henneberg, and P. Naude (2007). 'Trust and Reliance in Business Relationships,' European Journal of Marketing, 41(9/10), 1016-1032.

Omar, O., A. Kirby, and C. Blankson (2003). 'Acculturation and the Influence of Ethnicity on Market Orientation of African and Caribbean Companies in Britain,' The Service Industries Journal, 23(4), 81-97.

Palmatier, R. W., R. P. Dant, D. Grewal, and K. R. Evans (2006). 'Factors Influencing the Effectiveness of Relationship Marketing: A Meta Analysis,' Journal of Marketing, 70, 136-153.

Phillips, C., I. Doole, and R. Lowe (1994). International Marketing Strategy: Analysis, Development and Implementation. London: Routledge. 
Pires, G. and J. Stanton (2000). 'Marketing Services to Ethnic Consumers in Culturally Diverse Markets: Issues and Implications,' Journal of Services Marketing, 14(7), 607-618.

Rousseau, D. M., S. B. Sitkin, R. S. Burt, and C. Carmerer (1998). 'Not So Different After All: A Cross-Discipline View of Trust,' Academy of Management Review, 23, 393-404.

Sackmann, A. S. (1991). 'Uncovering Culture in Organizations', Journal of Applied Behavioral Science, 27(3), 295-317.

Sarasvathy, D. S. (2004). 'The Questions We Ask and the Questions We Care about: Reformulating Some Problems in Entrepreneurship Research', Journal of Business Venturing, 19, 707-717.

Saunders, M. N. K., D. Skinner, and R. J. Lewicki, (2010). 'Emerging Themes, Implications for Practice and Directions for Research,' In Organizational Trust: A Cultural Perspective. Eds. M. N. K. Saunders, D. Skinner, N. Gillespie, G. Dietz, and R. J. Lewicki. Cambridge: Cambridge University Press, 407-423.

Schoorman, F.D., R.C. Mayer, and J.H. Davis (2007). 'An Integrative Model of Organizational Trust: Past, Present, and Future', Academy of Management Review, 32, 344-54.

Schumann, J. H., F. Waggenheim, A. Stringfellow, and Z. Yang (2010). 'Drivers of Trust in Relational Service Exchange: Understanding the Importance of Cross-Cultural Differences,' Journal of Service Research, 13, 453-468.

Swift, S. J. (1999). 'Cultural Closeness as a Facet of Cultural Affinity: A Contribution to the Theory of Psychic Distance,' International Marketing Review, 16(3), 182-201.

Theron, E. and N. S. Terblanche (2010). 'Dimensions of Relationship Marketing in Business-to-Business Financial Services,' International Journal of Market Research, 52(3), 383-402.

Werbner, P. (1990). 'Renewing an Industrial Past: British Pakistani Entrepreneurship in Manchester', Migration, 8, 7-41.

Wong, A., and A. Sohal (2002). 'An Examination of the Relationship between Trust, Commitment and Relationship Quality,' International Journal of Retail \& Distribution Management, 30(1), 34-50.

Wright, T. L., M. L. Martin, and M. Stone (2003). 'Exploring the Characteristics, Attitudes to Targeting and Relationship Marketing of Small Ethnic Minority Businesses,' Journal of Targeting, Measurement and Analysis for Marketing, 12(2), 173-184. 
Zontanos, G., and R. A. Anderson (2004). 'Relationships, Marketing and Small Business: An Exploration of Links in Theory and Practice,' Qualitative Market Research: An International Journal, 7(3), 228-236. 
Figure 1.

\section{A Conceptual Model}

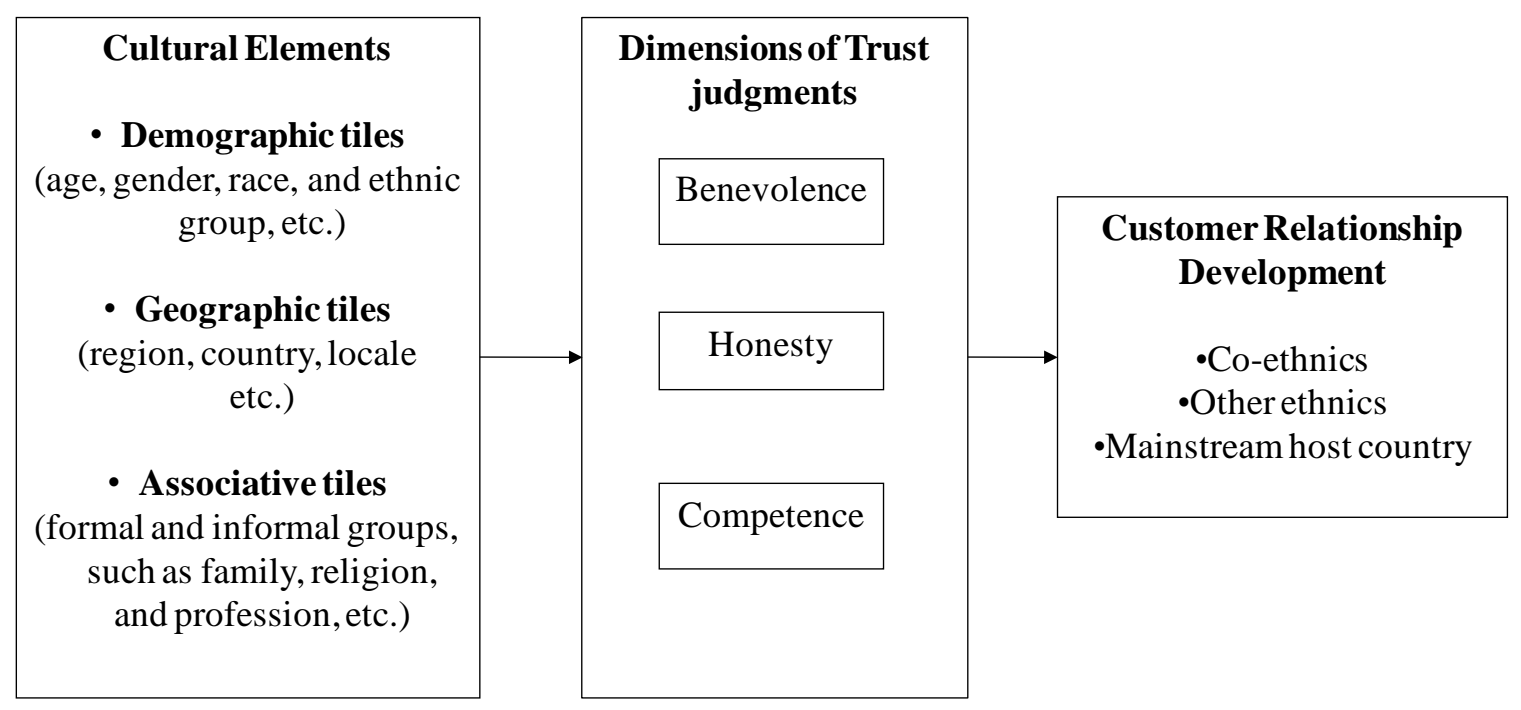


Figure 2.

Example Data Structure

\section{$1^{\text {st }}$ Order Concepts}

\section{$2^{\text {nd }}$ Order Themes}

\begin{abstract}
Aggregate
Dimensions
\end{abstract}

- Start conversations [with customers]

- Give [customers] attention

-Make customers feel at home

-Family atmosphere [always] helps

-Generous when sharing food

- Offer more than enough

-[Invite customers to] come and have a chat

-[Invite customers to] socialise

-Should not cheat [on customers]

- Follow fair trade practice

- Gain the trust [of customers]

-Establish good standards

-Buy good quality raw materials

-Invest in professionalism

-Work hard as a real professional

-No 'waffling' when [entrepreneur] taking to customer

-[Recognise ]customers are knowledgeable

-Make customers confident [entrepreneur] knows the business
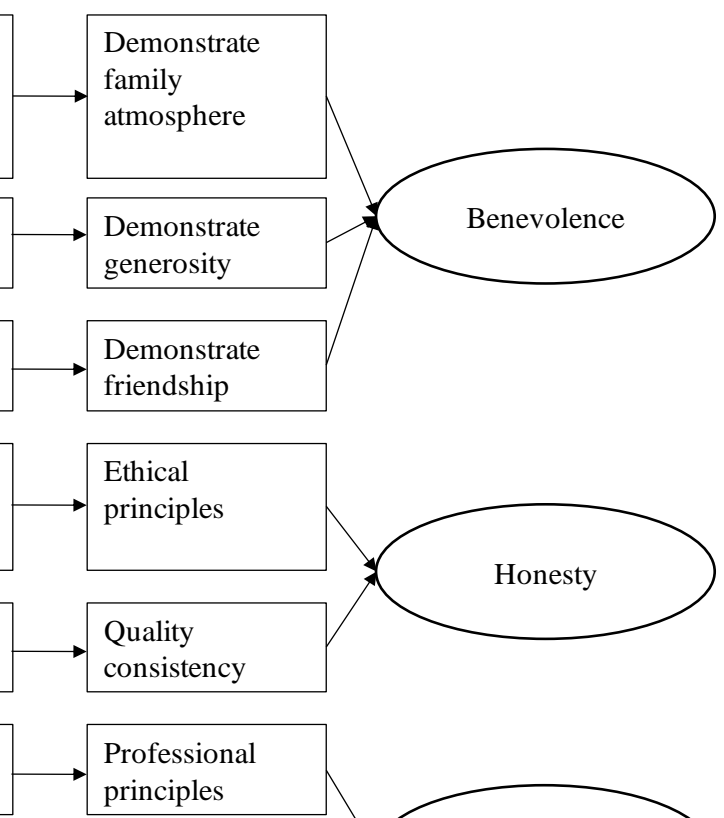

Demonstrate professionalism 
Figure 3.

\section{Theoretical framework}

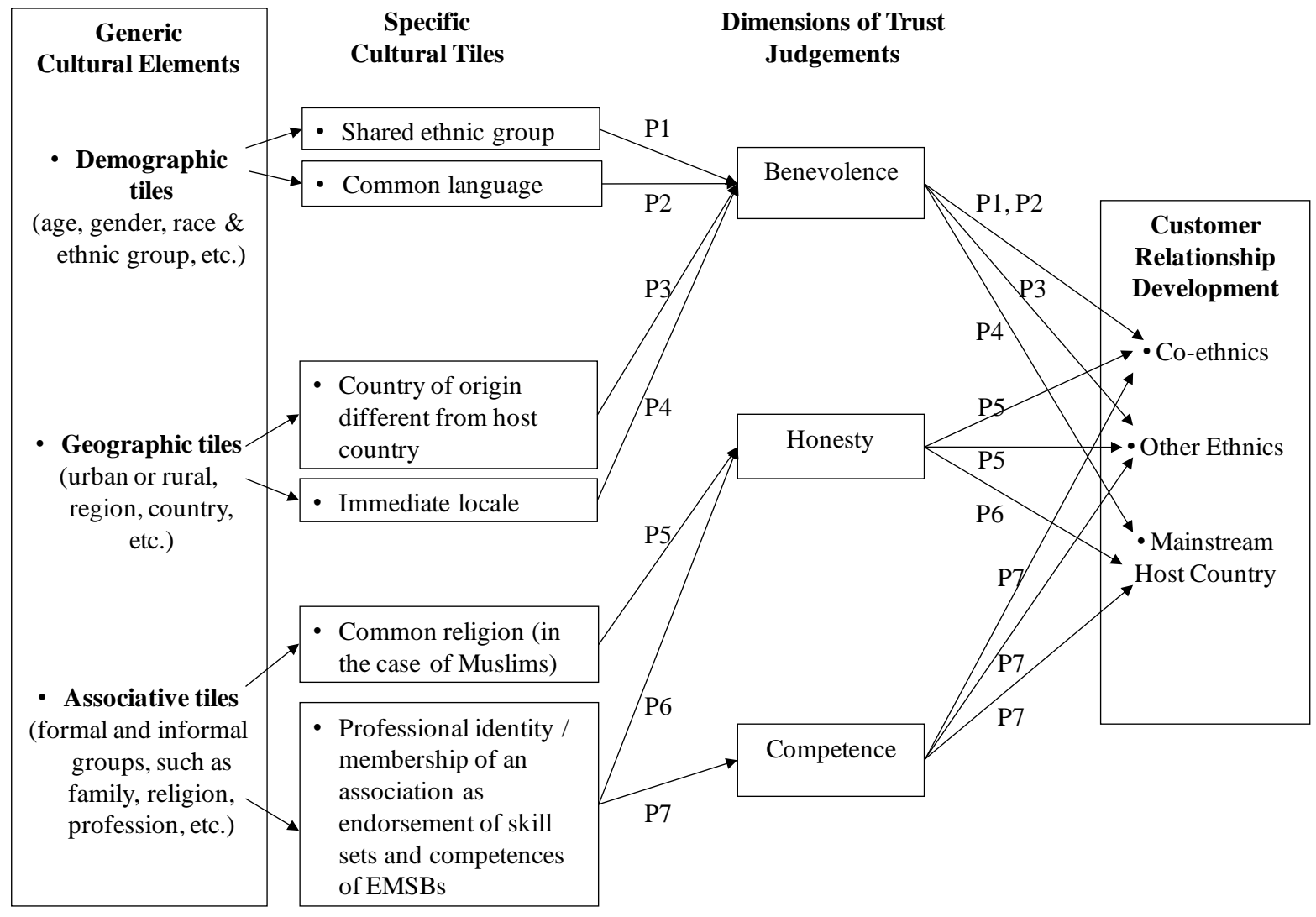


Table 1.

Examples of categorization of themes into aggregate trust dimensions

\begin{tabular}{|c|c|c|c|}
\hline & \multicolumn{3}{|c|}{ Dimensions of Trust } \\
\hline & Benevolence & Honesty & Competence \\
\hline $\begin{array}{l}\text { Theme } \\
\text { Example }\end{array}$ & $\begin{array}{l}\text { Demonstrate family atmosphere } \\
\text { 'I talk to customers informally; I talk } \\
\text { to them about football, traffic, } \\
\text { weather, family and develop an } \\
\text { informal relationship.' }\end{array}$ & $\begin{array}{l}\text { Ethical principles } \\
\text { Work ethics are important. You } \\
\text { should not cheat on your } \\
\text { customers... }\end{array}$ & $\begin{array}{l}\text { Professional principles } \\
\text { '.....They (customers) expect me to } \\
\text { represent their interests by responding } \\
\text { to their needs on time and doing my job } \\
\text { professionally.' }\end{array}$ \\
\hline $\begin{array}{l}\text { Theme } \\
\text { Example }\end{array}$ & $\begin{array}{l}\text { Demonstrate generosity } \\
\text { 'Generosity and sharing things are } \\
\text { part of our culture...' }\end{array}$ & $\begin{array}{l}\text { Quality consistency } \\
\text { 'We establish good standards by } \\
\text { buying good quality raw materials } \\
\text { from meat, burger, cheese } \\
\text { suppliers...' }\end{array}$ & $\begin{array}{l}\text { Professionalism } \\
\text { 'My difference from competitors is I } \\
\text { always invest in professionalism and } \\
\text { quality...' }\end{array}$ \\
\hline $\begin{array}{l}\text { Theme } \\
\text { Example }\end{array}$ & $\begin{array}{l}\text { Demonstrate friendship } \\
\text { 'We take the initiative and start off } \\
\text { conversations with our customers } \\
\text { about anything.' }\end{array}$ & & \\
\hline
\end{tabular}


Table 2.

Examples of categorization of concepts into cultural tiles

\begin{tabular}{|c|c|c|c|}
\hline & \multicolumn{3}{|c|}{ Primary Cultural Tile Categories } \\
\hline & Demographic & Geographic & Associative \\
\hline Tile & Shared Ethnic Group & Country of Origin & $\begin{array}{l}\text { Professional Identity/Membership of an } \\
\text { association as endorsement of skill } \\
\text { sets/competences }\end{array}$ \\
\hline Example & $\begin{array}{l}\text { 'Most of my customers are Turkish. } \\
\text { They trust me because I am Turkish } \\
\text { too...' }\end{array}$ & $\begin{array}{l}\text { 'We have many customers from the } \\
\text { Mediterranean and Middle East } \\
\text { region; Turkish Cypriots, Kurdish } \\
\text { and Arabs. We come from the same } \\
\text { region...' }\end{array}$ & $\begin{array}{l}\text { 'There are many plumbers around who } \\
\text { are not certified. My certification and } \\
\text { membership to the association of } \\
\text { Plumbing and Heating Contractors } \\
\text { make English customers realize that I } \\
\text { have no choice but to be honest...' }\end{array}$ \\
\hline Tile & Common Language & Immediate Locale & Religion \\
\hline Example & $\begin{array}{l}\text { '.... Turkish people come to me } \\
\text { because they can express themselves } \\
\text { in Turkish language...' }\end{array}$ & $\begin{array}{l}\text { '....we are more established in the } \\
\text { region. We are local. People in the } \\
\text { area know us...' }\end{array}$ & $\begin{array}{l}\text { 'Muslim customers know about my } \\
\text { religious background. They trust me, } \\
\text { they know that I would be honest with } \\
\text { them...' }\end{array}$ \\
\hline
\end{tabular}




\section{Appendix 1.}

\section{Interview Schedule}

1) Could you please describe how you develop your relationships with your customers?

2) How do different customer groups respond to different relationship marketing practices?

3) What is the role of trust in building this relationship? How did you build that close relationship?

4) What factors played an important role in building trust?

5) Can you describe the type of interactions you have with different customer groups and their frequency?

6) How important is cultural closeness to developing and maintaining trust with the customers?

7) What are the different elements of culture (for example, ethnicity, language, religion) that facilitate the development of trust with different customer groups?

8) How does your reputation or professional identity influence your relationship with the customers?

9) How do you see your competitive advantage over large firms in developing relationships with different customer groups?

10) Do you feel that you have invested a great deal in developing trust and relationship with different customer groups? What else could be done?

11) Do you consider your relationship with the customers to be successful? If so why, what are the things, in your opinion that make it successful? If not, what are the things that make it not successful?

12) If a friend were to ask your advice on 'gaining the trust of different groups of customers', what would you say? 